\title{
Jan Pedersen 2011. Subtitling Norms for Television: An Exploration Focussing on Extralinguistic Cultural References. Amsterdam/Philadelphia: John Benjamins. 242 pages. ISBN 978-90-272-2446-0
}

In the last decade the study of audiovisual translation has gained great interest, as one can notice taking a look at the list of new scientific articles, publications and national and international conferences devoted to these theme. The growing interest can be explained by the mesmerizing effect that the audiovisual material has on us and by the breathtaking role that it plays in our life. Television, cinema, computer games, internet, etc. are the audiovisual sources that play a major role in our lives and often the language in which they are produced is English. And even if English is the lingua franca of the global world, the audiovisual material needs to be translated in local languages in order to be fully understood. As Pedersen notes (1), Swedes watch an average of 2,5 hours of television a day much of which is subtitled. Audiovisual translation is then a very important factor in people's everyday life and consequently scholars find it important to tackle this subject and Perdersen's book does it very thoroughly.

Subtitling norms for television situates in the framework of the descriptive translation studies (DTS) as developed and defined by Toury $(1980,1991,1995)$ and it aims to discover and describe the norms that regulate the translation process that leads to the creation of subtitles for television programmes. The source language considered in the book is English and the target languages, i.e. the languages of the subtitles, are Swedish, Danish and Norwegian. The norms are empirically identified via the observation of what happens in an extended corpus, called the Scandinavian Subtitles Corpus, of 100 Anglophone films and TV programmes and Swedish, Danish and some Norwegian subtitled versions of these films and TV programmes.

The corpus is scrutinized to identify what Pedersen calls Extralinguistic Cultural References (or ECRs for short). These are words of group of words, also known in Translation Studies as realia or culture-bound words, used to refer to persons, foods, games, institutions, etc. that are generally recognizable by speakers belonging to one country, but not necessarily to other countries. As an example, Pedersen offers the expression Edwardian governess present in the ITV thriller Midsomer Murders (Pedersen 2011: 51). This expression requires from the translator the competence to recognize that it refers to the Edwardian era and, at the same time, the cultural knowledge of the English society sufficient to realize the sense of 'a teacher living and working in someone's home' as well as the class implications. The translator needs then to be competent in the English language and culture at the point that she can transform this culturally determined expression of the dialogue into a subtitle.

The reason why Pedersen choses ECRs as the focal point of his study is that they present a symptomatic translation problem, in fact, according to Pedersen, cultural references constitute one of the most important translation problems subtitlers deal with. Pedersen proposes a tripartite model to describe how ECRS are rendered: first he defines the concept, then he proposes a taxonomy of strategies to render the ECRs and finally he identifies the parameters that influence the choice of the translation strategies employed in the corpus.

The aforementioned definition of ECRs, broadly illustrated in the book, is clearly structured in a way that it will make possible for future scholars to adopt it. The second part of the model proposes a taxonomy of strategies to render the ECRs. The taxonomy, well presented in a clear scheme, distinguishes at a first level between Source and Target Oriented translations. Among the Source oriented translation we find at a first level Retention, Specification and Direct Translation as optional strategies. Among the Target oriented Strategies we find Generalization, Substitution and Omission as optional strategies. All these strategies are further divided into subcategories. One strategy does not belong to the Source and Target oriented groups, i.e. Official equivalent.

Pedersen calls Retention the strategy where an ECR is kept unchanged in the subtitle. It can 
be complete, adjusted to the needs of the target language requirements, marked or unmarked. He gives the example of the car called Cadillac Fleetwood whose name is retained in a subtitle as it is.

In Specification the ECR is rendered more specific either with an addition of information not present in the source text or with completion, f.i. in the case of explicated acronyms. Pedersen gives the example of the name Ian Botham that in the Swedish subtitle is rendered with Cricketspelaren Ian Botham (cricket player Ian Botham, my retranslation).

In Direct Translation the only change is represented by the language, without semantic alteration. The subcategories indicated in the scheme are calque or loan translation and shifted that in Pedersen's opinion is a more precise definition of literal translation. As an example of calque Pedersen gives Captain of police that in the Danish subtitle is rendered with politi-kaptajn instead of the more localized term 'kommissær'.

Under the category Target Oriented translation strategies Pedersen lists Generalization, Substitution and Omission.

The strategy Generalization makes the translation of the ECR in the subtitles less specific than the one in the source text. This can happen via the use of a superordinate term or a paraphrase. The example given by Pedersen comes from the TV series $M^{*} A^{*} S^{*} H$ where the ECR The Three Stooges has been replaced by a Swedish translation of the hypernym entertainment.

In Substitution, subcategorized in cultural and situational substitution, an ECR is replaced in the subtitle with something else, either belonging to the same culture, or not. The example here is the substitution of the ECR $N Y U$ (New York University) with the term $K U A$ (University of Copenhagen).

Omission is the strategy chosen by translator when they decide not to translate the ECR present in the source text.

To be able to translate an ECR with an Official Equivalent, an official decision by some authority is needed. Conversion of measurements would fall into this category.

After the identification of the translation strategies employed in the corpus, Pedersen identifies the parameters that influence their choice. These parameters are: Tranculturality, Extratestuality, Centrality, Polysemiotics, Media-specific constraints and Subtitling situation. This part of Pedersen's research is highly original. In fact if a taxonomy of translating strategies is not completely new in translation studies, the attempt to sum up the factors that influence the decision making of subtitlers when it comes to rendering ECRs, is an important step forward in the field. Pedersen tries to explain why an ECR has been rendered in a certain way in a subtitle, giving a relevant contribution to the theoretical discussion that is taking place in audiovisual translation studies.

Transculturality is the level of accessibility of an ECR in a different culture, related to the concept of cultural distance (the closer the culture, the broader the knowledge of its ECRs in a target culture). Translation problems are caused by Monocultural ECRs, i.e. the ECRS that are specific of a given culture and not recognized by the majority of the members of the target culture. Extratextuality refers to the possibility that ECRs are fictional and created by a text, or belong to the referential world extern to the text. Centrality refers to the importance of an ECR at the macro and micro-level. Polysemiotics is a parameter that subtitlers should consider because they translate audiovisual material, polysemiotic by nature. Images also convey meanings that can not be forgot. Media-specific constraints have to do with the switch from the spoken word of the dialogue to the written word of subtitles and to the condensation technically required in subtitles. The Subtitling Situation is a broad parameter that includes consideration such as the skopos, the genre, the style of the source text and also sociological consideration about the target group of the text.

Subtitling norms for television continues with the application to the corpus of the theoretical principles just presented. The analysis presented by Pedersen is very accurate, rich of explanations and certainly documented enough to constitute an example for scholars and students who will want to study culture and subtitles. The corpus consists of 100 Anglophone films and TV programmes with Swedish, Danish and Norwegian subtitles. Pedersen presents a lot of data extracted from it: 
the expected reading speed, the condensation rate, the subtitle quantity and density of the subtitles and he presents also the rendering of ECRs classified per translation strategies: the analysis identifies very thoroughly the subtitling norms in Scandinavian countries.

The details of the rich analysis can certainly be better evaluated by speakers of Scandinavian languages, but any scholar can appreciate the accuracy of the methodology and the richness of the analysis. Pedersen's example could easily be followed in further studies, possibly at an international level. It would be desirable to create a common practice to study the translation of ECRs in subtitles that could be compared and validate Pedersen's model.

A comment about the presentation of the corpus: as it often is the case, researchers involved in the same type of investigation are never content with the details they get to know about colleagues' methodology and in this case I would have loved to know how was the corpus collected, how was it catalogued and tagged, how were the data extracted and also simply how it looks like.

Pedersen concludes his study observing that it makes sense to talk about a pan-Scandinavian subtitling norm rather than national norms for Scandinavia. He proves that the Scandinavian subtitling norms have recently converged despite the increasing number of operators in the field and the broader offer of technology.

Subtitling norms for television is a relevant book that gives an important contribution to the study of ECRs in subtitles, taking into account the theoretical framework of Audiovisual Translation Studies. The book illustrates in great detail the theoretical state of the art, to give an original contribution to the question of the translation of realia. Scholars and students involved in translation studies are well aware of the relevance of this question and Pedersen offers a framework to frame it. Future studies will have to consider Pedersen's approach to further advance in the field. In fact in the field of AVT studies there is a bit the tendency to ignore methodologies and results proposed by previous scholars, whilst it would be desirable to study a common problem with a common methodology and a common framework. Pedersen's book could become such a standard in the study of ECRs. The fact that Pedersen's analysis is based on a Scandinavian corpus leaves a lot of space for comparison with other corpora, even though it would be hard for a single researcher to assemble such an imposing corpus. Personally, I would have liked that the question of Transculturality would be presented with a broader historical background, but again, this question is central in my own research and therefore no details are ever enough.

To conclude I want to add that the clear structure, the abundance of examples and the argumentative coherence of Subtitling norms for television help the reader to follow all the passages of the book and to understand its meanings. The iconic side includes nice drawings, tables and scheme that clarify the matter and make it more memorable.

\section{References}

Toury, G. 1980: In search of a theory of translation. Tel Aviv: Porter Institute for Poetics and Semiotics, Tel Aviv University.

Toury, G. 1991: What are Descriptive Studies into Translation Likely to Yield apart from Isolated Descriptions? In Translation studies: the state of the art. Rodopi.

Toury, G. 1995: Descriptive translation studies and beyond. Amsterdam; Philadelphia: J. Benjamins Pub. 
